The Egyptian Journal of Hospital Medicine (October 2019) Vol. 77 (1), Page 4748-4753

\title{
Interferon-Lambda 4 Gene Polymorphisms Predict Treatment Response in Egyptian HCV Genotype 4 Patients Exposed to Radiation \\ Hisham E Zidan ${ }^{1 *}$, Randa M Talaat ${ }^{2}$, Amal A A Ammar ${ }^{1}$, Moustafa A Sakr ${ }^{2}$ \\ ${ }^{1}$ Department of Medical Researches, Nuclear Material Authority, Cairo, ${ }^{2}$ Department of Molecular \\ Diagnostics and Theraputics, Genetic Engineering and Biotechnology Research Institute (GEBRI), \\ University of Sadat City, Menoufia, Egypt. \\ Corresponding author: Hisham E Zidan, email: hz1616@yahoo.com
}

\begin{abstract}
Background: Direct-acting antivirals (DAAs) has seen a significant increase of the count of patients with hepatitis C virus (HCV) clearing their infection. Interferon Lambda Four (IFNL4) polymorphism plays a distinguished role in spontaneous and treatment-output clearance of HCV infection.

Aim of this Work: This study aimed to assess IFNL4 polymorphism among hepatitis C Egyptian patients who were exposed to radiation, compared to normal by a polymerase chain reaction with restriction of fragment length polymorphism (PCR-RFLP) technique.

Materials and Method: This study included $50 \mathrm{HCV}$-positive Egyptian patients working in Egyptian Nuclear materials Authority treated with DAAs therapy. According to treatment, they were split into two groups. Group I included 40 patients with sustained viral response (SVR). Group II included 10 patients with no response (nSVR). Fifty healthy people served as controls. Liver function tests, complete blood count, evaluation of viral markers, HCVRNA by PCR, and evaluation for IFNL4 single nucleotide polymorphisms for rs368234815 were performed by PCRRFLP in all patients. Results: Of the 50 patients, 40 (80\%) achieved sustained virological response (SVR). Of the 23 patients with rs368234815 TT/TT genotype, 21 (91.3\%) achieved SVR, while in 27 patients with non- TT/TT genotypes, 19 (70.4\%) achieved SVR. The rs368234815 was a powerful predictor of SVR. However, in the present research individuals, the predictive power of this SNP was the same as that of rs12979860 SNP.

Conclusion: In Egyptian HCV-positive patients with genotype 4, IFNL4 rs368234815 SNP is an autonomous predictor of SVR to DAAs treatment.
\end{abstract}

Keywords: Interferon Lambda Four, hepatitis C, Polymerase Chain Reaction.

\section{INTRODUCTION}

Hepatitis c virus (HCV) infects more than 170 million people globally, $70 \%$ of whom become longterm carriers. Only a minority of infected people spontaneously clear the virus, while 30 to $60 \%$ develop chronic liver illness and a significant proportion develop chronic liver disease and a substantial percentage develops cirrhosis or even hepatocellular carcinoma (HCC). Egypt has the largest hepatitis $\mathrm{C}$ incidence in the world ${ }^{(1)}$. Ionizing radiation and hev infection communicate to boost the risk of $\mathrm{HCC}$ supermultiplicatively. Ionizing radiation at elevated concentrations of exposure considerably improves HCC hazards when hov is not identified at the same time. This fits into a pattern with other studies of interaction in hepatocarcinogenesis. Synergistic or greater than multiplicative interactions in HCC being reported when subjects are subjected to agents such as radiation that cause mainly genetic alteration, as well as agents such as hov and heavy drinking that trigger liver cell regeneration. People with $\mathrm{HCV}$ may therefore be particularly susceptible to exposure to radiation and vice versa ${ }^{(2)}$.

$\mathrm{HCV}$ treatment was tied to combination therapy consisting of pegylated interferon and ribavirin (PEGIFN and RBV). Recently, new antiviral agents known as

Received:4/7/2019

Accepted:4/8/2019 direct-acting antivirals (DAAs) have been developed and introduced for treatment of $\mathrm{HCV}$ infection. Although DAAs are more effective than PEG-IFN/RBV combination therapy given, these new treatments of $\mathrm{HCV}$ are not affordable and available in many countries. PEG-IFN and RBV still known to remain the alternative $\mathrm{HCV}$ treatment regimen ${ }^{(3)}$.

Egypt Demographic and Health Surveys (EDHS) assessed the incidence of antibodies among adults aged $15-59$ at $14.7 \%$ in 2009 and $10.0 \%$ in 2015 substantially greater than worldwide rates. To address this challenge, Egypt created a domestic HCV control strategy and established programs for $\mathrm{HCV}$ prevention and therapy. Following effective $99 \%$ discounted DAA pricing negotiations, Egypt introduced an ambitious domestic $\mathrm{HCV}$ therapy program aimed at treating more than 250,000 chronically infected people per year with the objective of attaining a domestic chronic infection incidence of $<2 \%$ by 2025 . Despite this advancement, current proof indicates that HCV transmission in Egypt continues, with greater rates of incidence compared to other nations ${ }^{(4)}$.

Diagnostic instruments, such as genotyping IFNL3 andIFNL4, can predict those most likely to spontaneously clear HCV that could be postponed in therapy. These instruments may also stratify people and 
ejhm.journals.ekb.eg

prioritize DAAs therapy to those less likely to react to interferon-containing regimens or recognize those likely to react well to shortened therapy ${ }^{(5)}$.

Evaluations of African American patients with HCV infection indicated that IFNL4 rs368234815 may be the strongest host genetic factor for prediction of $\mathrm{HCV}$ treatment response. Designing a simple, inexpensive and rapid method for genotyping of the IFNL4 rs368234815 polymorphism might be helpful for predicting response to treatment ${ }^{(6)}$. The polymerase chain reaction-restriction fragment length polymorphism (PCR-RFLP) method that had been developed for genotyping of rs368234815 is accurate, inexpensive, fast and simple to perform ${ }^{(3)}$.

\section{SUBJECTS AND METHODS}

In this study, the cohort consisted of 100 subjects; 50 healthy control included 21 (42\%) women and $29(58 \%)$ men and their ages ranged from 18 to 57 years and 50 patients with chronic HCV infection where $14(28 \%)$ were females and $72 \%$ were males received treatment by DAAs during the period from July 2016 to January 2018 and whose specimens were referred to the Egyptian Nuclear Material Authority Laboratory (located in Cairo, Egypt). According to the response to therapy, they were classified into two groups. The first group included patients with SVR: the chronic HCV patients who had received the therapy and had shown negative HCV-RNA after not less than 6 months of completion of a 24-week treatment course with DAAs. The second group included nonresponders to the therapy (no disappearance of HCV-RNA at the end of the 12 weeks).

\section{Ethical Approval:}

Informed consent was obtained from all patients before the study and this study was approved by the Ethical Committee of the Nuclear Material Authority, Cairo, Egypt. The study followed the principles of the Declaration of Helsinki.

\section{Treatment regiments}

Patients received triple combination therapy with $400 \mathrm{mg}$ sof once daily, Peg-INF $(180 \mathrm{mcg} / 0.5 \mathrm{ml}$; fixed dose/week) plus RBV (1000 mg for $\leq 75 \mathrm{Kg}$ or $1200 \mathrm{mg}$ for $>75 \mathrm{Kg}$ ) for 12 weeks.

\section{Blood sampling}

All chronic HCV patients were of genotype 4 by the INNoLiPA (Fujirebio Europe, NV, Ghent, Belgium) test. Two blood samples from each topic were acquired. In serum-separating pipes, the first sample was gathered. Blood was left to clot at room temperature, then centrifuged at 4000-6000 rpm. Serum was segregated for biochemical assessment (SGOT and SGPT). The second sample was collected in a clean and dry vacutainer tube with ethylene diamine tetra acetic acid
(EDTA) anticoagulant for hematology analysis (CBC) and IFNL4 rs368234815 genotypes distribution study.

\section{DNA extraction}

DNA extraction was done by using G-spin ${ }^{\mathrm{TM}}$ total DNA extraction kit according to manufacturer's instructions (Spain, Cat. No. 17045). In brief, samples were lysed and the DNA was captured on the spin columns provided. The DNA was washed, eluted and then stored at $-20^{\circ} \mathrm{C}$ until used in PCR amplification.

\section{IFNL4 Genotyping via PCR-RFLP}

IFNL4-F primer (5'-

GACGCAGGACCCCTTGGGACAGGA-3') and

IFNL4-R primer (5'-

TCTGGGCCGCAGTGGCCGCGAGG-3') used as a forward and reverse primer pair. The PCR reactions were performed using Accupower PCR PreMix. Amplified $100 \mathrm{ng}$ to $300 \mathrm{ng}$ of genomic DNA using 10 pmol of IFNL4-F and IFNL4-R primer pairs. The PCR temperature profile was as follows: $94^{\circ} \mathrm{C}$ for 5 minutes, 40 cycles of $94^{\circ} \mathrm{C}$ for 20 seconds, $60^{\circ} \mathrm{C}$ for 30 seconds, and $72^{\circ} \mathrm{C}$ for 30 seconds, followed by $72^{\circ} \mathrm{C}$ for 5 minutes. For the RFLP analysis, the PCR product of rs368234815 was digested with 10 units of MspA1I (New England BioLabs) restriction endonuclease (RE) for more than 1 hour. The digested PCR products were separated on 3\% agarose gel alongside the GeneRuler 100-bp DNA Ladder (Thermo FisherScientific Inc.). The agarose gel was stained with the addition of $0.5 \mathrm{~mL}$ of DNA safe Stain (CinnaGen Co.) into each $100 \mathrm{~mL}$ of agarose gel. In each run of PCR-RFLP genotyping of rs368234815, as a control for enzymatic activity, a single rs368234815- $\Delta \mathrm{G} / \Delta \mathrm{G}$ DNA specimen was included.

\section{Statistical analysis}

The data were collected, tabulated, and analyzed using statistical package for the social sciences (SPSS Inc., SPSS Statistics for Windows Version 21.0. Chicago, USA) on an IBM compatible computer. The c2-test was conducted to study the association between two qualitative variables. Fisher's exact test was used in the analysis of $2 \times 2$ contingency tables.

The Student t-test was used for comparison between two groups having normally distributed quantitative variables. The Mann-Whitney U-test was conducted as a nonparametric test of significance for comparison between two groups having abnormally distributed quantitative variables. Analysis of variance was used as a parametric test for comparison between more than two groups having normally distributed quantitative variables. The Kruskal-Wallis test was used as a nonparametric test of significance for compariso between more than two groups having not normally distributed quantitative variables. Regression analysis is a statistical process for estimating the relationships among variables ${ }^{(7)}$. 


\section{RESULTS}

Table (1): Comparison between HCV patients and controls regards to the laboratory findings.

\begin{tabular}{|c|c|c|c|c|}
\hline \multirow{2}{*}{ Parameters } & \multicolumn{2}{|c|}{ Mean \pm SD } & \multirow{2}{*}{ t-test } & \multirow{2}{*}{ P Value } \\
\cline { 2 - 3 } & Control & Patients & & \\
\hline TLC $\left(\mathbf{1 0}^{\mathbf{3}} / \boldsymbol{\mu L}\right)$ & $4.99 \pm 1.36$ & $6.74 \pm 1.89$ & 5.31 & $<0.001^{\mathrm{HS}}$ \\
\hline HB $(\mathbf{g} / \mathbf{d L})$ & $14.42 \pm 1.92$ & $13.63 \pm 1.97$ & 2.03 & $<0.05^{\mathbf{S}}$ \\
\hline PLT $(\mathbf{1 0} / \mathbf{c m m})$ & $229.62 \pm 39.82$ & $220.60 \pm 57.54$ & 0.91 & $>0.05^{\mathrm{NS}}$ \\
\hline AST $(\mathbf{U} / \mathbf{L})$ & $25.36 \pm 3.76$ & $30.68 \pm 13.59$ & 2.67 & $<0.05^{\mathrm{S}}$ \\
\hline ALT $(\mathbf{U} / \mathbf{L})$ & $23.12 \pm 3.68$ & $30.58 \pm 15.85$ & 3.24 & $<0.001^{\mathrm{HS}}$ \\
\hline
\end{tabular}

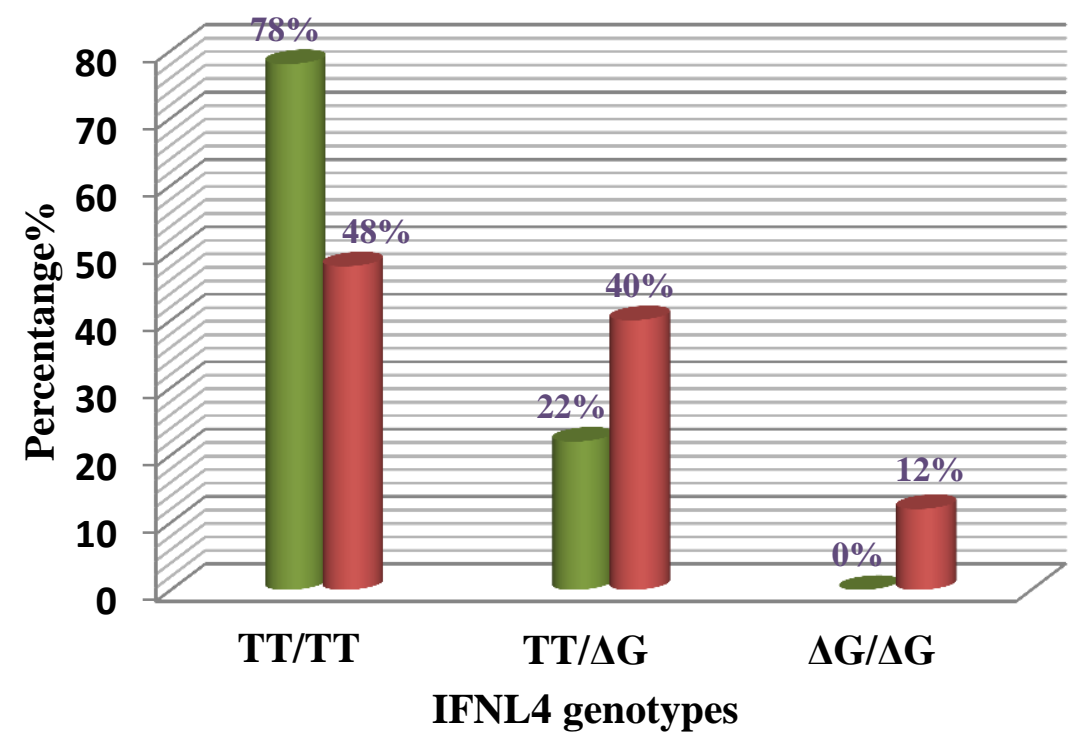

- Control

Patients

Figure (1): Distribution of the IFNL4 genotypes among hepatitis C virus (HCV) patients and healthy controls.

Table (2): Comparison between genotypes distribution and allele frequencies of IFNL4 polymorphism (rs368234815) and sustained viral response in hepatitis C virus patients (SVR and nSVR groups)

\begin{tabular}{|c|c|c|c|c|}
\hline $\begin{array}{c}\text { IFNL4 Polymorphism } \\
\text { rs368234815 }\end{array}$ & $\begin{array}{c}\text { SVR } \\
(n=40)\end{array}$ & $\begin{array}{c}\text { nSVR } \\
(n=10)\end{array}$ & OR (95 \% CI) & P-value * \\
\hline \multicolumn{5}{|l|}{ Genotype [n (\%)] } \\
\hline TT/TT & $21(52.5 \%)$ & $2(20 \%)$ & $\operatorname{Ref}(1.00)$ & \\
\hline $\mathbf{T T} / \Delta \mathrm{G}$ & $15(37.5 \%)$ & $5(50 \%)$ & $3.5(0.60-20.52)$ & $0.165^{\mathrm{NS}}$ \\
\hline$\Delta G / \Delta G$ & $4(10 \%)$ & $3(30 \%)$ & $7.88(0.99-63.31)$ & $0.052^{\mathrm{NS}}$ \\
\hline \multicolumn{5}{|l|}{ Dominant model $^{\text {a }}$} \\
\hline $\mathrm{TT} / \mathrm{TT}$ & $21(52.5)$ & $2(20.0)$ & $\operatorname{Ref}(1.00)$ & \\
\hline $\mathrm{TT} / \Delta \mathrm{G}+\Delta \mathrm{G} / \Delta \mathrm{G}$ & $19(47.5)$ & $8(80.0)$ & $4.42(0.83-23.47)$ & $0.081^{\mathrm{NS}}$ \\
\hline \multicolumn{5}{|l|}{ Recessive model $^{\text {b }}$} \\
\hline $\mathrm{TT} / \mathrm{TT}+\mathrm{TT} / \Delta \mathrm{G}$ & $36(80.0)$ & $7(70.0)$ & $\operatorname{Ref}(1.00)$ & \\
\hline$\Delta \mathrm{G} / \Delta \mathrm{G}$ & $4(20.0)$ & $3(30.0)$ & $3.86(0.70-21.15)$ & $0.12^{\mathrm{NS}}$ \\
\hline \multicolumn{5}{|l|}{ Alleles [n (\%)] } \\
\hline TT & $57(71.0)$ & $9(45.0)$ & Ref. (1.00) & - \\
\hline$\Delta \mathrm{G}$ & $23(29.0)$ & $11(55.0)$ & $3.03(1.11-8.28)$ & $0.03^{s}$ \\
\hline
\end{tabular}




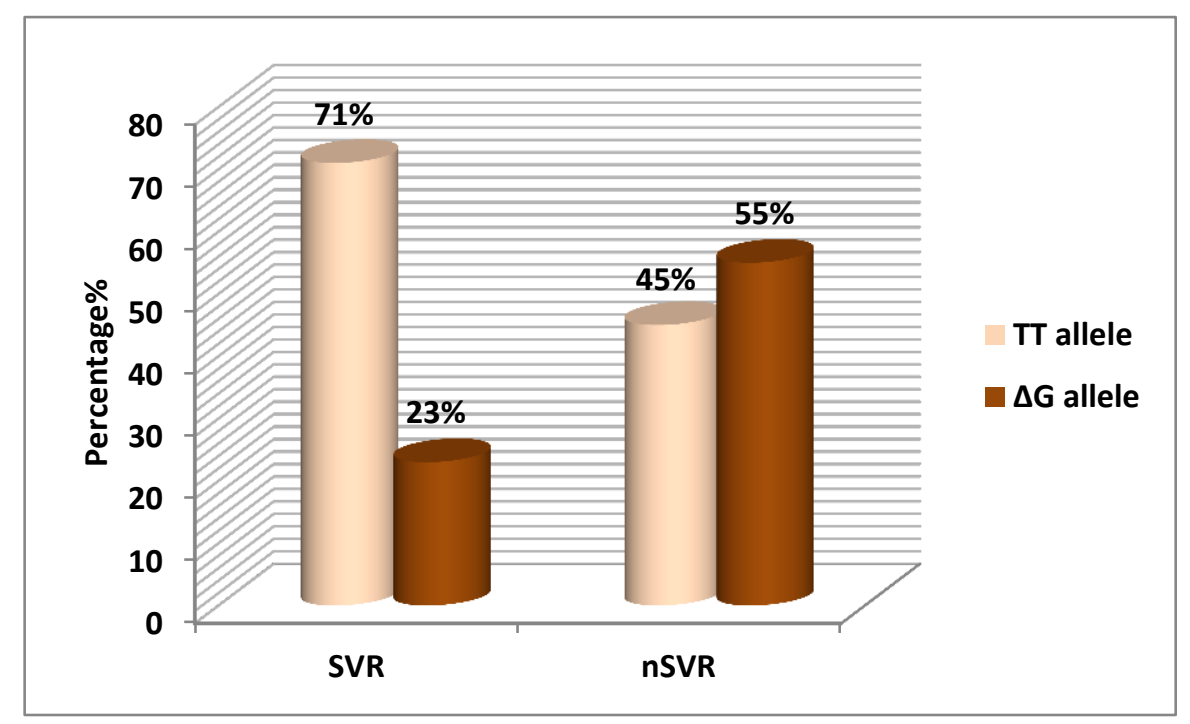

Figure (2): Alleles frequency of IFNL4 polymorphism (rs368234815) in SVR and nSVR groups.

Table (3): Comparison between IFNL4 genotypes and laboratory parameters for HCV patients

\begin{tabular}{|c|c|c|c|c|c|}
\hline & \multicolumn{3}{|c|}{ IFNL4 genotypes } & \multirow[b]{2}{*}{$\begin{array}{c}\text { Kruskal- } \\
\text { Wallis Test }\end{array}$} & \multirow[b]{2}{*}{ P Value } \\
\hline & $\begin{array}{c}\text { TT/TT } \\
(\mathbf{N}=23)\end{array}$ & $\begin{array}{c}\text { TT/ } / \Delta G \\
(\mathbf{N}=20)\end{array}$ & $\begin{array}{l}\Delta \mathbf{G} / \Delta \mathbf{G} \\
(\mathbf{N}=7)\end{array}$ & & \\
\hline Age $(X \pm$ SD $)$ & $50.61 \pm 9.01$ & $50.70 \pm 9.98$ & $43.71 \pm 9.62$ & 3.235 & $0.198^{\mathrm{NS}}$ \\
\hline TLC $(X \pm$ SD $)$ & $6.70 \pm 1.68$ & $6.69 \pm 2.29$ & $7.03 \pm 1.45$ & 0.228 & $0.892^{\mathrm{NS}}$ \\
\hline $\mathrm{HB}(\mathrm{X} \pm \mathrm{SD})$ & $13.77 \pm 2.16$ & $13.34 \pm 1.98$ & $14.01 \pm 1.32$ & 1.209 & $0.546^{\mathrm{NS}}$ \\
\hline PLTs $(\mathrm{X} \pm \mathrm{SD})$ & $230.48 \pm 55.53$ & $210.10 \pm 85.21$ & $218.14 \pm 65.26$ & 1.122 & $0.571^{\mathrm{NS}}$ \\
\hline $\operatorname{AST}(X \pm S D)$ & $27.43 \pm 9.97$ & $30.25 \pm 13.42$ & $42.57 \pm 19.16$ & 4.855 & $0.088^{\mathrm{NS}}$ \\
\hline $\operatorname{ALT}(X \pm S D)$ & $25.87 \pm 10.54$ & $31.6 \pm 16.44$ & $43.14 \pm 22.72$ & 4.935 & $0.085^{\mathrm{NS}}$ \\
\hline
\end{tabular}

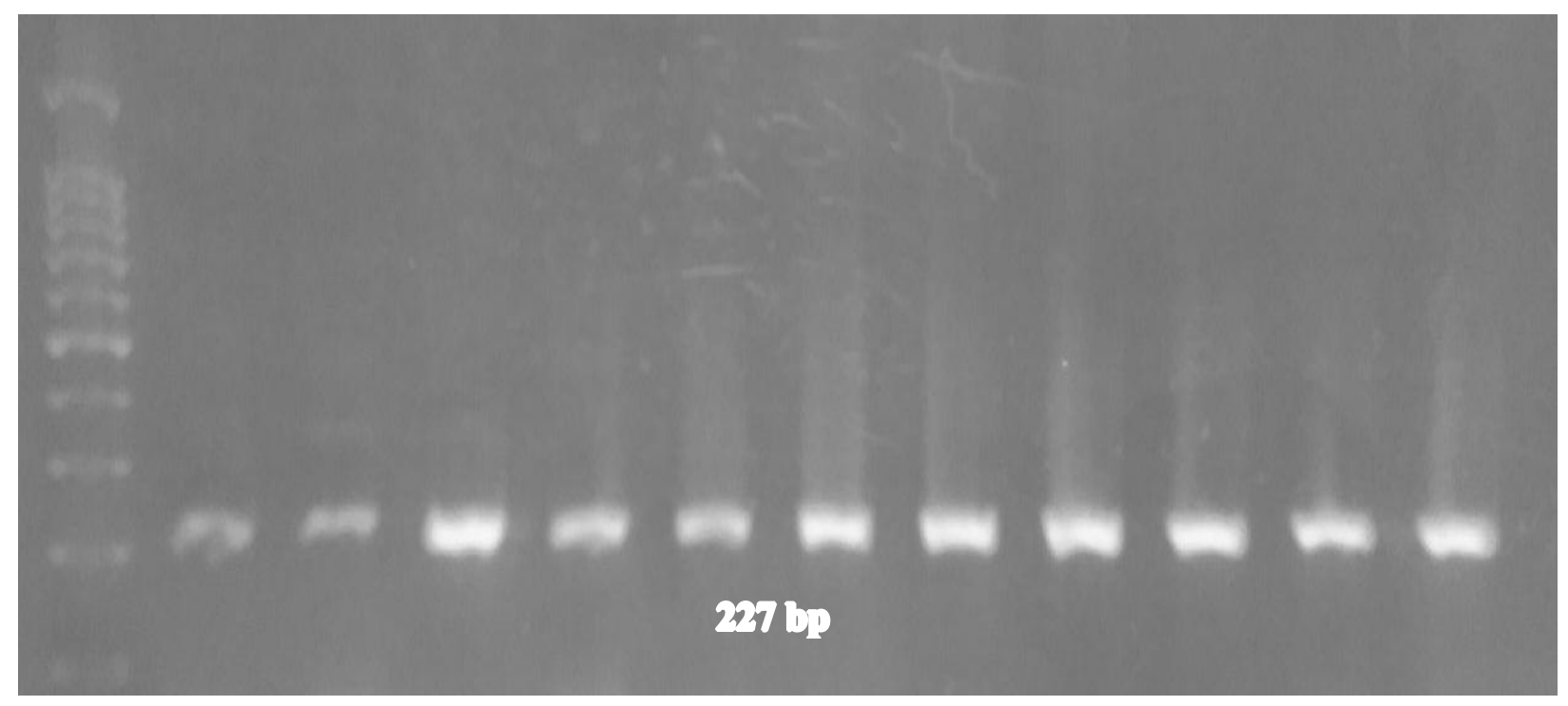

Figure (3): Agarose gel electrophoresis illustrated the PCR-RFLP products for the IFNL4 gene polymorphism. Lane 1 corresponds to $100 \mathrm{bp}$ molecular weight marker, the rest are nondigested PCR product at $227 \mathrm{bp}$. 


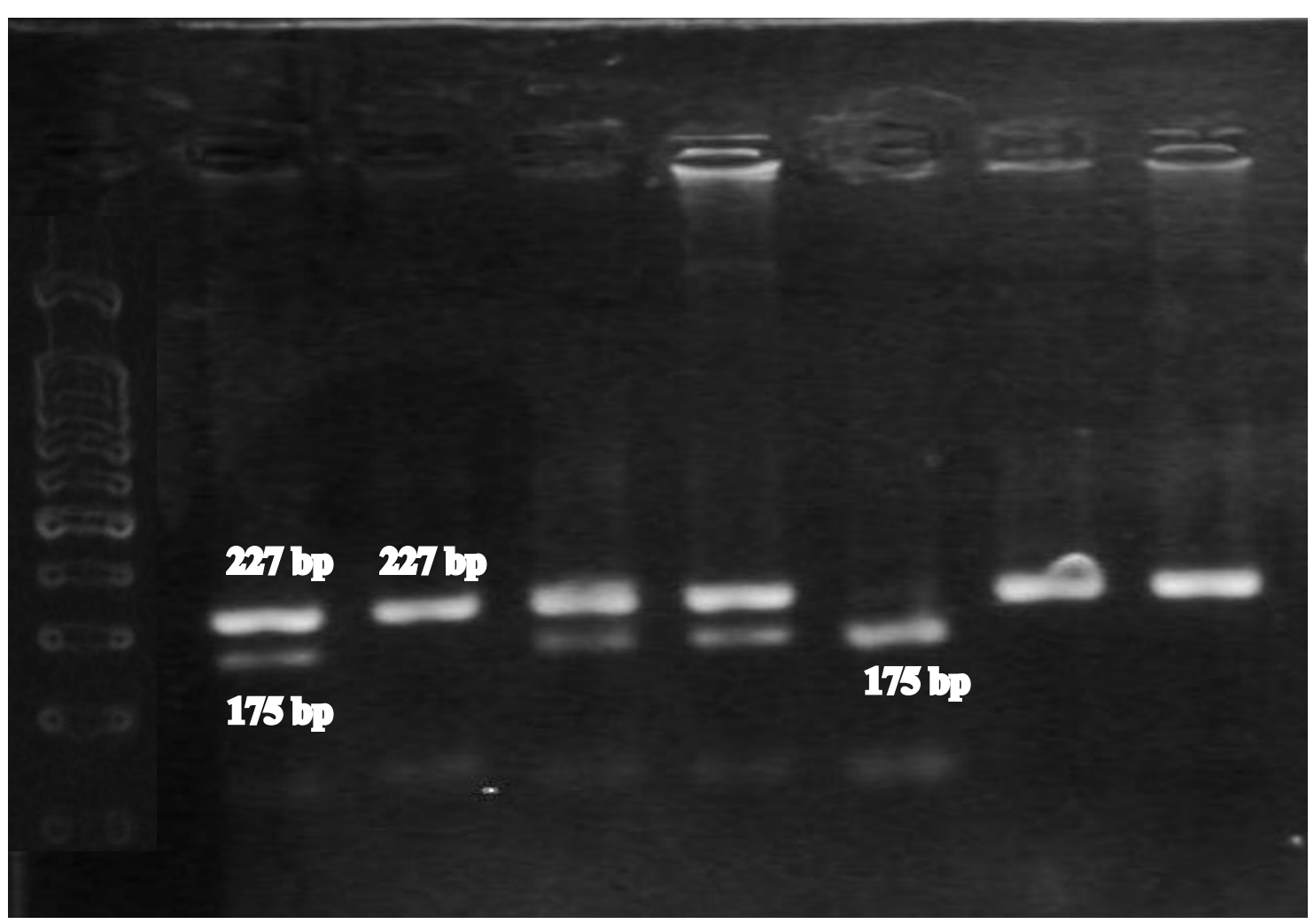

Figure (4): PCR-RFLP products on agarose gel electrophoresis illustrating for the IFNL4 gene polymorphism after difestion by MspA1I.

Lane 1 corresponds to 100 bp molecular weight marker. Lanes 3, 7, and 8 correspond to blood samples from homozygous TT/TT participants. Lanes 2,4 and 5 correspond to blood samples from homozygous TT/ $\Delta \mathrm{G}$ participants. Lane 6 correspond to blood samples from heterozygous $\Delta \mathrm{G} / \Delta \mathrm{G}$ participants.

\section{DISCUSSION}

The present work aimed to assess the predictive value of the IFNL4 polymorphism in the treatment of chronic $\mathrm{HCV}$ in Egyptian patients and its allele frequency in HCV patients compared with controls.

The mean age was $41.28 \pm 8.11$ and $48.18 \pm$ 8.15 for control and patients respectively, and the difference is considered to be extremely statistically significance $(\mathrm{p}<0.001)$.

Among the baseline laboratory values, alanine aminotransferase (ALT) and aspartate aminotransferase (AST) levels were significantly higher in patients than in controls $(\mathrm{P}<0.01)$. Hematology values showed that there was a significant difference as regards $\mathrm{HB}$ $(\mathrm{P}<0.05)$, highly significant difference as regards TLC $(\mathrm{P}<0.01)$ and no significant difference as regards PLT $(\mathrm{P}>0.05)$ between control and patients group as shown in table (1).

In This study, the 50 chronic HCV patients, the rs12979860 TT/TT, TT/ $\Delta \mathrm{G}$, and $\Delta \mathrm{G} / \Delta \mathrm{G}$ genotypes were present in 48,40 , and $12 \%$ of patients, respectively, but for controls the frequency was 78, 22, and $0 \%$ for $\mathrm{TT} / \mathrm{TT}, \mathrm{TT} / \Delta \mathrm{G}$, and $\Delta \mathrm{G} / \Delta \mathrm{G}$, respectively, with no statistically significant difference between them (Fig. 1).

IFNL4-F and IFNL4-R primer pair were used for PCR-RFLP genotyping of IFNL4 rs368234815, which amplified the $226 \mathrm{bp} / 227$ bp DNA fragment (Figure 3). Digestion of this product with MspA1I in individuals with the $\Delta \mathrm{G} / \Delta \mathrm{G}$ genotype showed 2 fragments of $175 \mathrm{bp}$ and $51 \mathrm{bp} ; 3$ fragments of 227, 175, and $51 \mathrm{bp}$ in the $\mathrm{TT} / \Delta \mathrm{G}$ genotype and a 227-bp fragment in the TT/TT genotype (Figure 4).The frequency of IFNL4 genotype in genotype 4 Egyptian patients working in Egyptian Nuclear Authority was: 23 $\mathrm{TT} / \mathrm{TT}(46 \%), 20 \mathrm{TT} / \Delta \mathrm{G}(40 \%), 7 \Delta \mathrm{G} / \Delta \mathrm{G}(14 \%)$ (Table 4). Nearly similar results were reported in many recent studies. Pouryasin et al. ${ }^{(3)}$ reported that the frequencies of TT/TT, TT/ $\Delta \mathrm{G}$ and band $\Delta \mathrm{G} / \Delta \mathrm{G}$ were $44.8 \%, 37.9 \%$, and $17.3 \%$, respectively. Galmozzi et al. ${ }^{(8)}$ found that the genotypic frequencies of rs368234815 variant was $37 \%$ for TT/TT, $49.5 \%$ for $\mathrm{TT} / \Delta \mathrm{G}$ and $13.5 \%$ for $\Delta \mathrm{G} / \Delta \mathrm{G}$. While, Backus et al. ${ }^{(9)}$ showed that among 92 African Americans, 43.5\% (40) had $\Delta \mathrm{G} / \Delta \mathrm{G}$ genotype, $52.2 \%$ (48) had $\Delta \mathrm{G} / \mathrm{TT}$ genotype and $4.3 \%$ (4) had TT/ TT genotype. The comparison between different IFNL4 
The Egyptian Journal of Hospital Medicine (October 2019) Vol. 77 (1), Page 4748-4753

genotypes (TT/TT, TT/ $\Delta \mathrm{G}$, and $\Delta \mathrm{G} / \Delta \mathrm{G}$ ) in $\mathrm{HCV}$ patients where there was no significant difference as regards Age, TLC, HB, PLTs, AST and ALT (Table 3). In this study, the distribution pattern of IFNL4 genotypes among $\mathrm{HCV}$ patients as regards response to treatment was $40(80 \%)$ of the studied patients achieved an SVR, whereas $10(20 \%)$ did not. Of the 40 patients with an SVR, 21 had genotype TT/TT, 15 had genotype $\mathrm{TT} / \Delta \mathrm{G}$, and four had genotype $\Delta \mathrm{G} / \Delta \mathrm{G}$ with no statistically singnificant difference $(\mathrm{P}>0.05)$. However, there was a significant difference between SVR and nSVR as regards the IFNL4 alleles, as the frequency of the TT allele was higher in SVR than in nSVR (71\% vs. $45 \%$ ) and the $\Delta \mathrm{G}$ allele was lower in HCV patients than in controls (29\% vs. 55\%) (Table 6).

Prokunina-Olsson et al. ${ }^{(10)}$ showed that the polymorphism rs368234815 $(\Delta \mathrm{G})$ resulted in a frame shift mutation and therefore produced a new gene designated as interferon-lambda 4 (IFNL4). Homozygous individuals with IFNL4 TT genotype could not create this gene. Researchers have indicated that IFNL4 $\Delta \mathrm{G}$ genotype is correlated with poorer treatment reaction relative to TT genotype.

\section{CONCLUSION}

The IFNL4 polymorphism is an independent predictor of SVR to DAAS in Egyptian HCV patients with genotype 4 . Besides, increasing the chances of achieving SVR, determining IFNL4 SNPs before initiating treatment will be cost-effective and will reduce adverse effects.

\section{REFERENCE}

1. Omar M, Metwally M, El-Feky H, Ahmed I, Ismail M, Idris A (2017): Role of intrafamilial transmission in high prevalence of hepatitis C virus in Egypt. Hepat Med., 9: 27-33.
2. Sharp GB, Mizuno T, Cologne JB, Fukuhara T, Fujiwara S, Tokuoka S et al. (2003): Hepatocellular carcinoma among atomic bomb survivors: significant interaction of radiation with hepatitis $\mathrm{C}$ virus infections. Int J Cancer, 103: 531-7.

3. Pouryasin M, Sharafi H, Behnava B, Alavian SM, Keshvari M, Pouryasin A (2017): A simple PCR-RFLP method for genotyping of IFNL4 rs368234815 polymorphism in patients with chronic hepatitis C. Lab Med., 48 (1): 51-56.

4. Kouyoumjian SP, Chemaitelly H, Abu-Raddad LJ (2018): Characterizing hepatitis $\mathrm{C}$ virus epidemiology in Egypt: systematic reviews, meta-analyses, and meta-regressions. Sci Rep., 8: 1661.

5. Lamoury F M J et al. (2015): Interferon $\lambda 3$ and 4 Genotyping Using High-Resolution Melt Curve Analysis Suitable for Multiple Clinical Sample Types. The Journal of molecular diagnostics, 17 (5): 583-9.

6. Wu Q, Wang C, Chen EQ, Tang H, Li ZZ, Lei XZ (2015): Interferon lambda 4 polymorphism predicts sustained viral response in hepatitis $\mathrm{C}$ virus patients irrespective of hepatitis $\mathrm{C}$ virus genotypes, ethnicity or treatment regimen: results from a metaanalysis. Hepat Mon., 15 (12): e32707.

7. Morton R, J. Richard H, Mc C (2001): A study guide to epidemiology and biostatistics, 5th ed. Maryland: Aspen publication, Gaithersburg., Pp: 71-74.

8. Galmozzi E, Facchetti F, Perbellini R, Aghemo A (2014): High-resolution melting assay for genotyping of IFNL4-associated dinucleotide variant rs368234815. Clin Microbiol Infect., 20 (11): O936-O938.

9. Backus LI, Shahoumian TA, Belperio PS et al. (2018): Impact of IFNL4- $\Delta \mathrm{G}$ genotype on sustained virologic response in hepatitis $\mathrm{C}$ genotype 1 patients treated with direct-acting antivirals. Diagn Microbiol Infect Dis., 92 (1): 34-36.

10. Prokunina-Olsson L, Muchmore B, Tang W, Pfeiffer RM, Park H, Dickensheets H et al. (2013): A variant upstream of IFNL3 (IL28B) creating a new interferon gene IFNL4 is associated with impaired clearance of hepatitis C virus. Nat Genet., 45: 16471. 